\title{
COMPARATIVE STUDY \& PERFORMANCE ANALYSIS OF AODV, R-AODV \& PHR-AODV IN MANET
}

\author{
Nilesh Chandra', Awadhesh Kumar ${ }^{2}$ \\ ${ }^{1}$ KNIT, Sultanpur \\ ${ }^{2}$ Professor, KNIT, Sultanpur
}

\begin{abstract}
A MANET (Mobile Ad-Hoc Network) is the collection of mobile nodes and it's formed by using these mobile nodes. MANET supports infrastructure less communication architecture. It doesn't have any central access point or control center. In MANET every mobile node act as router and as well as intermediate node, sender and receiver. If the destination node is out of sender communication range than message reach to destination by Multi-hop technology. Mobile nodes are free to move and that cause dynamic nature of topology. There are various routing protocol for forwarding message towards the destination node such as $A O D V, D S D V, D S R$ and many more. In this paper we try to compare AODV and their improved version R-AODV and PHR-AODV. We compare these routing protocol based on some performance metrics like PDR, DELAY, CONTROL OVERHEAD and ENERGY CONSUMED.
\end{abstract}

Keywords:- $A O D V, R-A O D V, P H R-A O D V, M A N E T$

\section{INTRODUCTION}

As we know MANET is the collection of nodes and these nodes are responsible for creating infrastructure less communication network. These nodes may be static or mobile in nature. MANET is dynamic in nature due to free movement of these participating nodes. MANET supports multi-hop technology in routing process. These are various routing protocol available for dynamic nature of MANET network. AODV is the simple and old routing protocol for MANET. With the time many improvement comes in the AODV routing protocol and become more efficient and reliable routing protocol.

R-AODV Is the modified version of AODV routing protocol . R-AODV supports multiple reply packets where AODV supports the unicast route reply. Due to this factor performance of network in terms of PDR is improved.

These is lack of security in previous version of AODV routing protocol. So to overcome these problems we introduce PHR-AODV and decrease the intrusion rate of network.

\section{ROUTING PROTOCOL}

\subsection{AODV (AD-HOC on Demand Distance Vector)}

AODV is the on-demand reactive routing protocol. AODV is the single path routing protocol and support unicast reply message. AODV use sequence number technique for loop free routing in the network. AODV routing protocol have two phase one is ROUTE DISCOVERY and other is ROUTE MAINTAINCE.

When sender want to send data to destination node then sender initiate route-discovery process and sender node create RREQ packet and send to each neighbor node. When intermediate node received RREQ packet and it is not destination node then create reverse path towards sender and they again forward to their each neighbor nodes. This process continued till packet reach to destination node. Intermediate node discard duplicate RREQ packet by matching sequence number, destination id and sender id

When packet reach to destination node then destination node create RREP packet and send to sender node and this RREP packet goes through reverse route define by intermediate node.

During the communication if any link break or nodes moved from network then error occurred and that increase packet loss, delay and affect the overall performance of network. When any node detect problem in network then it generate RERR packet and send to sender node. When sender node received RERR packet then stop the communication and reinitiate route-discovery process and again start the communication.

\section{Algorithm Step}

AODV ( S, D , Data , EED, Bandwidth ) // Route Discovery Phase

\{ Source $\mathrm{S}$ initiates the RREQ packet and search neighboring nodes in the direction of destination $\mathrm{D}$;

If ( next-hop!=D \&\& Loop free )

\{ Source $\mathrm{S}$ broadcast the RREQ packet to all the neighboring nodes and continues till destination is not explored.

else

\{ Destination D is reached \} 
In the cache of the direct/intermediate nodes retrieve the routes from route caches. Add these routes in the route record and then generate the route reply packets in that order .// Route Reply Phase

If the route/s is/are found \{ Maintain a list of all discovered routes as LR.

RA-AODV ( LR , EED, BW , Hop count ) ; \} // AODV provisioning Reliability Phase being called here else

$\{$ Destination node D not reachable may be due to high mobility of nodes and network partitioning; \}

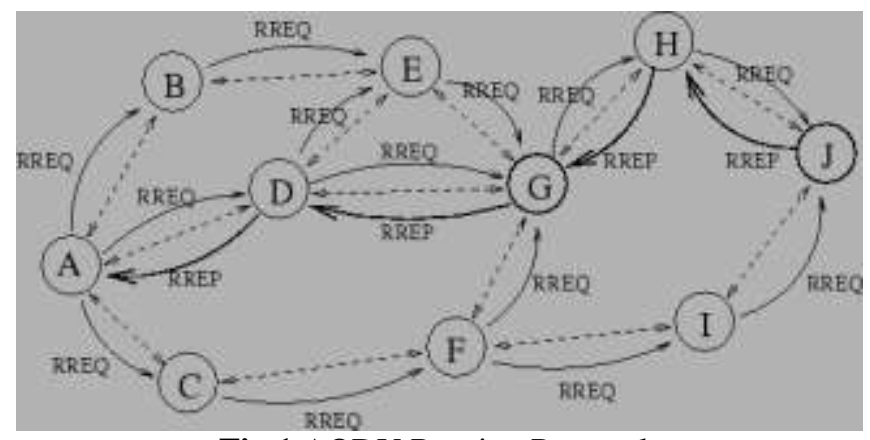

Fig 1 AODV Routing Protocol

\subsection{R-AODV (Reverse- AODV)}

Reverse AODV is the improved version of basic AODV routing protocol. As we know AODV routing protocol support unicast route reply, so in any case during communication route reply packet loss then sender wait for some time period and then restart the route discovery process. It means more route reply packet loss leads more route discovery process.

To overcome this problem we enhance the AODV routing protocol and support multiple route reply packet. So if any route reply packet loss then sender node get route reply from other route.

In Reverse AODV routing protocol transmission of RREQ packet is same as AODV routing protocol. When RREQ packets reach to destination node then destination node creates R-RREQ packet and starts route discovery process for searching sender node. When the source node received first R-RREQ packet then sender node start data transmission and keep other route reply for further use in case of link failure or node movement from communicating network.

Packet format of RREQ packet of R-AODV is same as AODV RREQ packet. The packet format of R-RREQ packet is given below.

Table 1 Packet format of R-RREQ packet

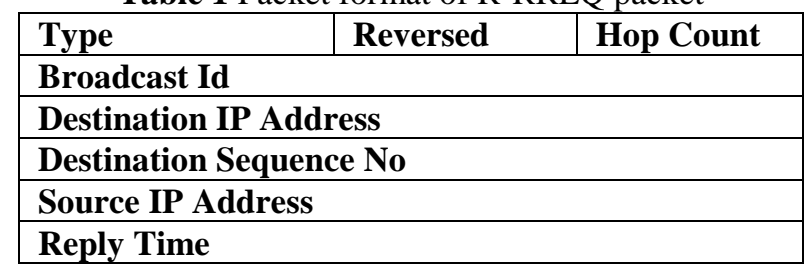

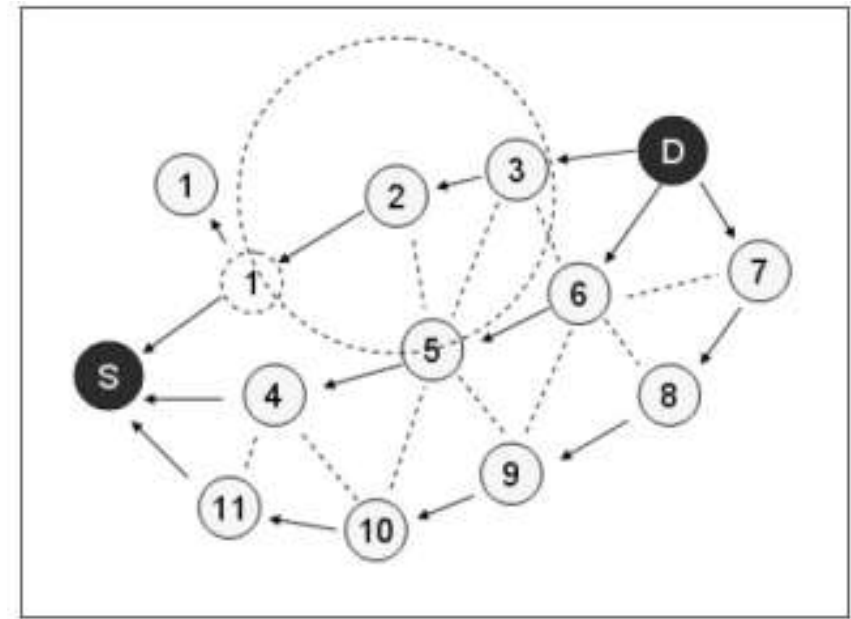

Fig 2 R-RREQ packet in Reverse AODV

In this figure we see that " $S$ " is the source node and " $D$ " is the destination node. When D received RREQ packet then it create R-RREQ packet and send to their neighbor node "3,6 \&7" Then these neighbor node forward R-RREQ packet to their neighbor node until packet reach to source node. Here source node received first route reply from neighbor node "1" then S start data transmission through path $\mathrm{S}->1->2->3$ $>\mathrm{D}$ and saved other route reply. Let assumed node 1 moved out from network then data transmission stop and packet not received by node $\mathrm{D}$. Then Source node select other route reply path and resume data transmission rather than restart route discovery process. This activity reduce delay and increased packet delivery ratio.

\subsection{PHR-AODV (Path Hoping Based AODV)}

PHR-AODV is the reactive routing protocol same as AODV and R-AODV routing protocol. PHR-ADOV is just extension of Reverse AODV routing protocol. PHR-AODV routing protocol increased the security level of protocol and protect data from attack of malicious node which are present in the network and PHR-ADOV also helps in load distribution over the network.

Packet format of RREQ and R-RREQ packets are same as $\mathrm{R}-\mathrm{AODV}$ routing protocol and route discovery process is also same as Reverse AODV route discovery process.

In route discovery process source node generate RREQ packet and send to their neighbor node and these neighbor node forward RREQ packet to their neighbor node until it reach to destination node. RREQ packet contain information like Source node address, Destination node address, source sequence number, request time, hop count and broadcast Id. When the RREQ packet reaches to destination node then destination node starts route discovery process again to find the source node and find fresh route from destination to source node. R-RREQ packet contains information like source address, Destination Address, Reply Time, Source sequence number, Destination sequence number and Broadcast Id. 
When the first R-RREQ packet reach to Source node then source node not immediate start data transmission like RAODV. Source node wait for some amount of time and keep all route reply in the table and after completion of that waiting time source node arrange these route reply in ascending order based on their hop-count value.

Now source node start data transmission on all available paths starting from least hop-count value path. In any stage of communication link failure or node failure occurred then source node eliminate that faulty path from route table and resume data transmission with left routing path. In the figure 3 we see that $\mathrm{S}$ is the source node and D is the Destination node and there are three paths from source to destination node.

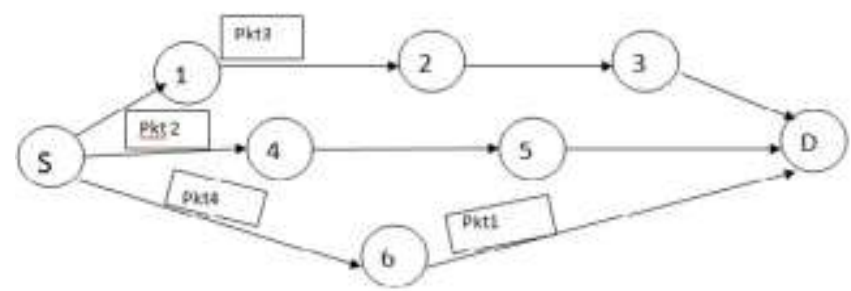

Fig 3. PHR-AODV Routing

First path from source to destination is $\mathrm{S}->1->2->3->\mathrm{D}$, second path is $\mathrm{S}->4->5->\mathrm{D}$ and last one is $\mathrm{S}->6->\mathrm{D}$. Source node sent first packet through path3 then second packet through path 2 and $3^{\text {rd }}$ packet through path 1 and next packet through path 3 again and process continue during data transmission.

Let assumed node 5 is malicious node and data transmission take place using this node in AODV and R-AODV then there is $100 \%$ data loss in both routing protocol. While in PHR-AODV data transmitted through all available path. So according to figure there is three path from source to destination node then data loss is $(1 / 3) * 100=33 \%$. It means PHR-AODV save $77 \%$ data.

PHR-AODV provide analytical and effective method to estimate security level of network and load distribution. The Probability of malicious node in network is equal to ( $\mathrm{Nrp}^{*}$ $\mathrm{Nm})$ / Ntotal. And malicious node intrusion rate is $\mathrm{Pi}=$ $\mathrm{Pm} . / \mathrm{Np}$. Where Nrp is number of node in routing path, $\mathrm{Nm}$ is number of malicious node and Ntotal is number of total node in the network. $\mathrm{Np}$ is the number of path from source to destination

\section{SIMULATION AND PERFORMANCE}

\section{METRICS}

Here we discuss the simulation model and various performance metrics. We consider many performance metrics and evaluate their value. In our paper we consider pdr, delay, control overhead and energy consumed as performance metrics.
Table 2. Simulation Parameter

\begin{tabular}{|l|l|}
\hline Simulation Time & $200 \mathrm{Sec}$ \\
\hline Routing protocols & AODV, R-AODV,PHR-AODV \\
\hline Area of Terrain & $1500 * 1500$ \\
\hline Number of nodes & $20,30,40,50,60$ \\
\hline Type of Traffic & TCP,UDP \\
\hline Size of Packet & 512 byte \\
\hline MAC Type & IEEE 802.11 \\
\hline $\begin{array}{l}\text { Transmission } \\
\text { Range }\end{array}$ & 250 meter \\
\hline Transmission rate & 6 Packet/Sec \\
\hline Antenna Type & Omni Antenna \\
\hline Propagation Type & Two Ray Ground \\
\hline Queue Type & Queue/DropTail/PriQueue \\
\hline Queue Length & 100 \\
\hline Mobility Model & Random way Point \\
\hline
\end{tabular}

\section{RESULT ANALYSIS}

\subsection{PDR}

\section{Aggregate PDR Vs Routing Protocol}

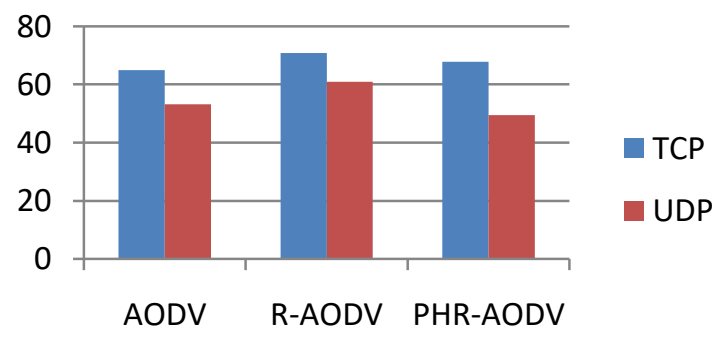

\subsection{End to End Delay}

\section{Aggregate Delay Vs Routing Protocol}

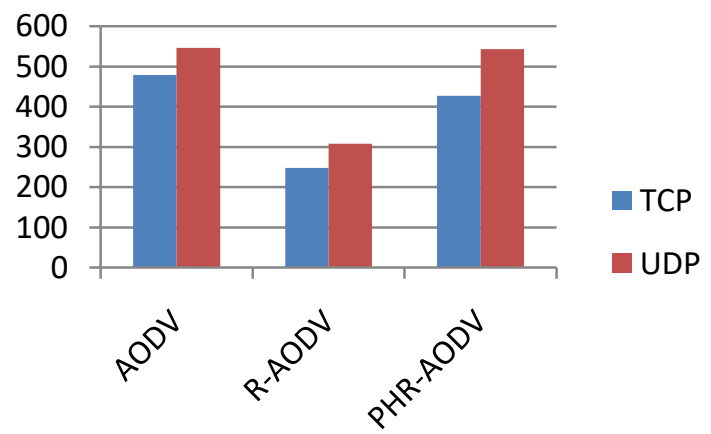




\subsection{Control Overhead}

Aggregate Control Overhead Vs Routing Protocol

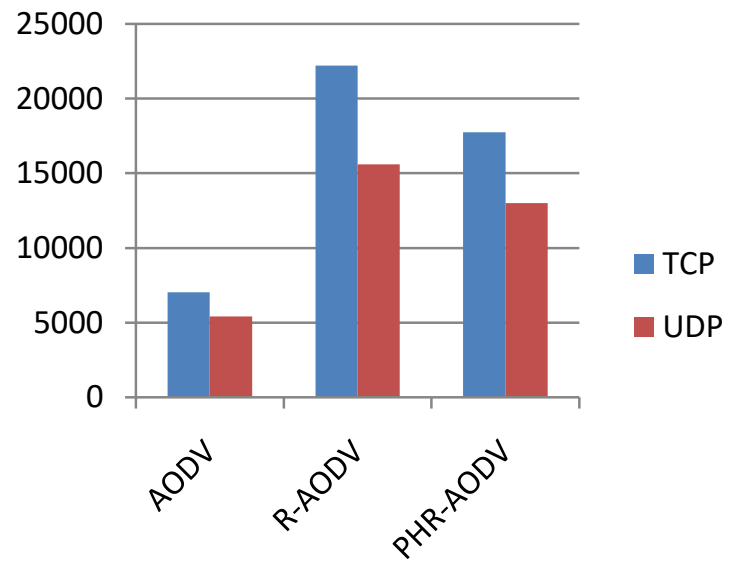

\subsection{Energy Consumed}

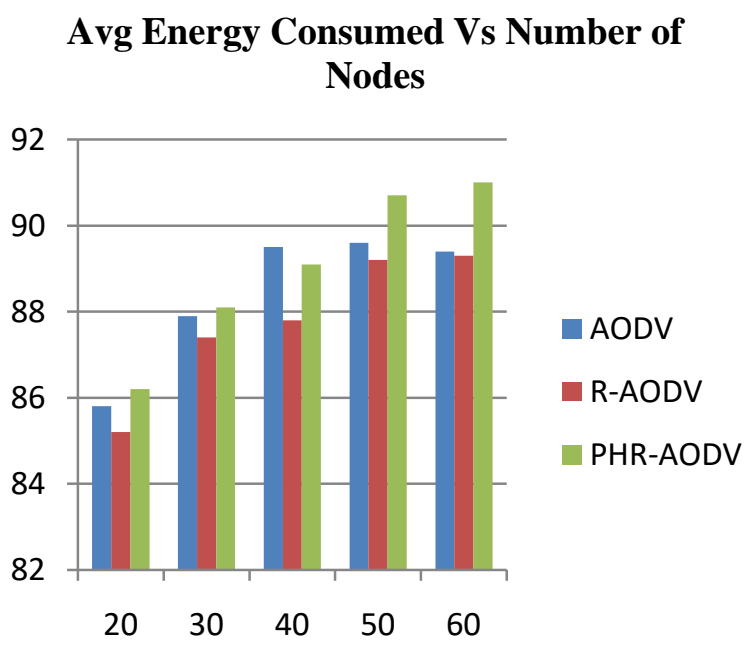

In terms of PDR (Packet Delivery Ratio), R-AODV with TCP connection perform better than AODV and PHRAODV.

In terms of End to End Delay, R-AODV with TCP connection have less delay than AODV and PHR-AODV.

In terms of Control Overhead, AODV with UDP connection have less overhead than R-AODV and PHR-AODV with TCP and UDP connection.

After analysis theses routing protocol we find that R-AODV with TCP connection perform well with comparison of AODV and PHR-AODV in terms of PDR and End to End DEALY. While in terms of Control overhead AODV with UDP connection perform better than R-AODV and PHRADOV. In terms of Energy consumed R-AODV consumed less energy in comparison of AODV and PHR-AODV.
Table 3 Comparison of routing table

\begin{tabular}{|l|l|l|l|}
\hline & AODV & $\begin{array}{l}\text { R- } \\
\text { AODV }\end{array}$ & $\begin{array}{l}\text { PHR- } \\
\text { AODV }\end{array}$ \\
\hline PDR & LOW & HIGH & MEDIUM \\
\hline DELAY & HIGH & LOW & MEDIUM \\
\hline $\begin{array}{l}\text { CONTROL } \\
\text { OVERHEAD }\end{array}$ & LOW & HIGH & MEDIUM \\
\hline $\begin{array}{l}\text { ENERGY } \\
\text { CONSUMED }\end{array}$ & MEDIUM & LOW & HIGH \\
\hline
\end{tabular}

As we describe malicious node in the network, the intrusion rate is depend on number of nodes. This intrusion rate is decrease with increase of number of nodes in the network. Intrusion rate also decreased with decreased of active malicious node.

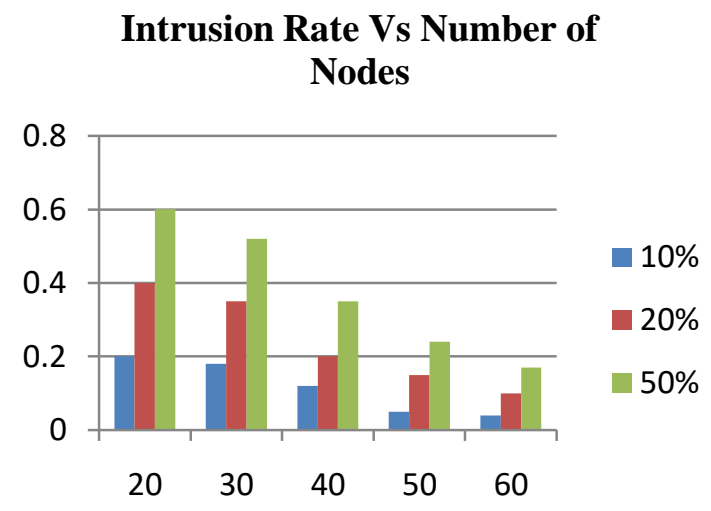

\section{CONCLUSION}

In this paper we compare the performance of AODV, RAODV and PHR-AODV based on various performance metrics such as pdr, delay, control overhead and energey consumed. As result we find R-AODV with TCP connection performs well with comparison of AODV and PHR-AODV in terms of PDR and End to End DEALY. While in terms of Control overhead AODV with UDP connection perform better than R-AODV and PHR-ADOV. In terms of Energy consumed R-AODV consumed less energy in comparison of AODV and PHR-AODV.

\section{FUTURE SCOPE}

In future we try to enhance PHR-AODV and increase PDR and reduce DELAY, CONTROL OVERHEAD and ENERGY COMSUMED entity.

\section{REFERENCE}

[1] C. Perkins, E. Belding-Royer Ad hoc on-Demand Distance Vector (AODV) Routing, RFC 3561, July 2003.

[2] Chonggun Kim, ElmurodTalipov, and ByoungchulAhn, "A Reverse AODV Routing 
Protocol in Ad Hoc Mobile Networks", LNCS 4097, pp. $522-531,2006$.

[3] C. K.-L. Lee, X.-H.Lin, and Y.-K. Kwok, "A Multipath Ad Hoc Routing Approach to Combat Wireless Link Insecurity," Proc. ICC 2003, vol. 1, pp. 448-452, May 2003.

[4] S.-J. Lee and M. Gerla, "Split Multipath Routing with Maximally Disjoint Paths in Ad Hoc Networks," Proc. ICC 2001, vol. 10, pp. 3201-3205, June 2001.

[5] M. K. Marina and S. R. Das "On-Demand Multi Path Distance Vector Routing in Ad Hoc Networks," Proc. ICNP 2001, pp. 14- 23, Nov. 2001.

[6] NS, The UCB/LBNL/VINT Network Simulator(NS),http://www.isi.edu/nsnam/ns/, 2004.

[7] Zhi Li and Yu-Kwong Kwok, "A New Multipath Routing Approach to Enhancing TCPSecurity in Ad Hoc Wireless Networks" in Proc. ICPPW 2005. [1] Elizabeth M. Royer and Chai-KeongToh, "A Review of Current Routing Protocols for Ad Hoc Mobile Wireless Networks," IEEE Personal Communications, Vol. 6, No. 2, pp. 46-55, April 1999.

[8] C.E. Perkins and E. M. Royer, "Ad hoc on-demand distance vector routing" in Proc. WMCSA New Orleans, LA, pp. 90-100, Feb. 1999.

[9] M. K. Marina and S. R. Das "On-Demand Multi Path Distance Vector Routing in Ad Hoc Networks" in Proc. ICNP 2001, pp. 14- 23, Nov. 2001.

[10] Nasipuri and S. R. Das, "On-Demand Multipath Routing for Mobile Ad Hoc Networks" Proc. ICCN 1999, pp. 64-70, Oct. 1999.

[11] Tarique, M., Tepe, E., SasanAdibi, and ShervinErfani, "Survey of multipath routing protocols for Mobile Ad-hoc networks", Journal of Network and Computer Applications, 32:1125-1143, 2009.

[12] Chonggun Kim, ElmurodTalipov and ByoungchulAhn, "A Reverse AODV Routing Protocol in Ad Hoc Mobile Networks," LNCS 4097, pp. 522-531, 2006.International Journal of Wireless \& Mobile Networks (IJWMN) Vol. 6, No. 5, October 2014.

[13] Pravanjan Das and Upena D Dalal, "A Comparative Analysis of AODV and R-AODV Routing Protocols in MANETS", International Journal of Computer Applications 72(21):1-5, June 2013.

[14] KhafaeiTaleb and KhafaieBehzad, "The Effect of Number of Hops per Path on Remind Energy in MANETs Routing Protocols," International Journal of Computer Applications vol. 43, no. 24, pp. 23-28, April 2012 